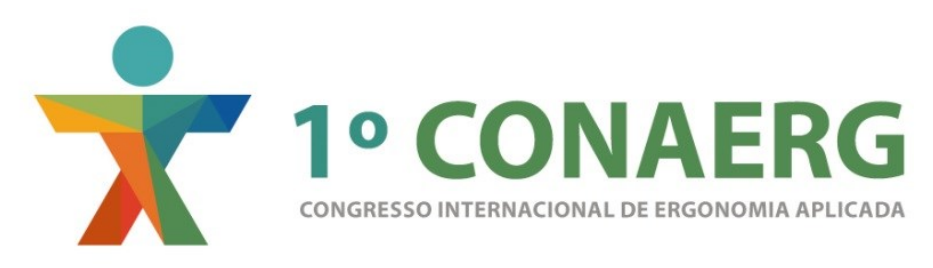

\title{
ANÁLISE COMPARATIVA DA ACESSIBILIDADE EM ILPIs
}

\author{
Marie Monique Paiva (1); Ademário Santos Tavares (2); \\ Mariana Oliveira (3); Vilma Villarouco (4) \\ (1) UFPE, Doutoranda em Design \\ e-mail: mariem.paiva@gmail.com \\ (2) UFPE, Doutorando em Design \\ e-mail: ademariojr@hotmail.com
}

(3) UFPE, arquiteta

e-mail: marianacfoliveira@hotmail.com

(4) UFPE, Pós-Doutora em Engenharia

e-mail: villarouco@hotmail.com

\begin{abstract}
RESUMO
A acessibilidade é condição fundamental para vida de qualquer ser humano. No caso dos idosos, pode representar mais do que a possibilidade de ir e vir; visa a promoção de uma melhor qualidade de vida, quer seja no ambiente residencial ou institucional. Este artigo tem o objetivo de evidenciar as características da infraestrutura de seis instituições de longa permanência para idosos com sistemas administrativos diferentes. Através da metodologia ergonômica MEAC e do método de acessibilidade MEA foram encontrados diversos problemas de não conformidade com a NBR 9050, evidenciando a falta da aplicação de preceitos ergonômicos em ambientes para idosos.
\end{abstract}

\begin{abstract}
Accessibility is fundamental to any human being's life. In the case of the elderly, it may represent not only the possibility of coming and going, but also the promotion of a better quality of life, whether in residential or institutional environment. This article aims to highlight the infrastructure features of six Long-Term Stay Institutions for the Elderly with different administrative systems. Through the application of ergonomic methodology MEAC and accessibility method MEA, several unconformity problems with NBR 9050/2004 were found, highlighting the lack of application of ergonomic principles in environments for the elderly.
\end{abstract}

\section{INTRODUÇÃO}

O envelhecimento humano constitui-se em um processo inexorável, progressivo e gradativo, que acomete as pessoas em função de múltiplos fatores de ordem genética, biológica, sociocultural, psicológica e ambiental (ZIMERMAN, 2000; NERI, 2008). 
Estima-se, segundo dos Santos Ferreira (2011), que o idoso de 60 anos tem perda do tempo de reação de $20 \%$ em relação a jovens de 20 anos. Também a capacidade de acomodação visual sofre significativo declínio do foco para objetos, passando de $8 \mathrm{~cm}$ em jovens para 50 a $100 \mathrm{~cm}$ em idosos de 60 anos.

A qualidade de vida do idoso interage com aspectos pessoais, de saúde, e ambientais, repercutindo em suas funções e atividades que determinam sua autonomia e independência. Assim, a capacidade funcional do idoso pode ser comprometida de acordo com seu nível de fragilidade e também com as barreiras/interferências arquitetônicas presentes nos espaços físicos (PERRACINI, 2006). O usuário e seu ambiente físico constituem um sistema indissociável e simbiótico, onde as interações acontecem de modo simultâneo e recíproco (PINHEIRO \& ELALI, 2011). Nesse contexto, a ergonomia do ambiente construído se apresenta como de fundamental importância na promoção do conforto, bem-estar e segurança dos idosos, tornando os ambientes acessíveis e adequados à luz do desenho universal e aspectos legais.

Este artigo evidencia o diagnóstico de seis avaliações ergonômicas realizadas em instituições de longa permanência para idosos da Região Metropolitana do Recife, Pernambuco. Embora tenham a mesma função de assistência às pessoas da terceira idade, foram avaliadas ILPIs de diferentes características, dentre elas o formato das edificações e os serviços que são disponibilizados para os idosos.

\section{ERGONOMIA DO AMBIENTE CONSTRUÍDO E O ENVELHECER}

O comportamento humano é influenciado pelo ambiente físico, em relação simultânea, recíproca e contínua com seu usuário (ELALI, 2010). As reações humanas são distintas entre as pessoas devido aos aspectos biológicos, socioculturais e afetivos, próprios de cada uma delas (PINHEIRO \& ELALI, 2011).

Segundo Perracini (2009) o ambiente é o maior responsável pela funcionalidade na velhice, devendo oferecer segurança, promover a interação social e propiciar bemestar ao idoso em ambiente acolhedor e agradável. O ambiente concorre para a qualidade de vida das pessoas, impactando no desenvolvimento das atividades como elemento facilitador ou limitador (BINS ELY, 2003; WAHL \& WEISMAN, 2003; VILLAROUCO, 2001).

É nesse contexto que a ergonomia do ambiente construído se insere como agente mitigador das limitações impostas pelo processo de envelhecimento com o surgimento de alterações sensório-motoras e percepto-cognitivas, assim como de disfunções crônico-degenerativas. Nessa direção, a melhoria da qualidade de vida dos usuários é fator dependente da qualidade ambiental.

Para Mont'Alvão \& Villarouco (2011), a ergonomia do ambiente construído vai além das questões físicas relacionadas aos espaços; a qualidade espacial é resultante do entendimento da arquitetura e do design envolvendo múltiplos fatores, como acessibilidade, orientabilidade, design e arranjo de mobiliário e projeto de iluminação. 


\subsection{Desenho universal e legislação em ambientes físicos de moradia coletiva}

O conceito de Desenho (ou Design) Universal considera a diversidade humana com o maior número de pessoas na concepção e adequação de produtos ou ambientes (BINS-ELY et al., 2002), ampliando sua abrangência maior que a acessibilidade para seu uso e usufruto (SILVA \& CARDOSO, 2015).

É importante que tais produtos, ambientes e sistemas estejam disponíveis para toda a população, qualquer que seja o objetivo ou necessidade de sua utilização e independente de suas características físicas. Aliás, estas características podem tanto facilitar quanto impedir a consecução dos objetivos do usuário durante o usufruto de ambientes e produtos (STEINFELD \& MAISEL, 2012). Suas limitações físicas somadas às inadequações observadas constituem-se em verdadeiras barreiras, e ambos afetando o desempenho do usuário tanto fisicamente quanto psicologicamente.

Para um envelhecimento ativo é fundamental considerar o ambiente construído em que vive o usuário, ressaltando condições de acessibilidade e adaptabilidade como garantia de interação das pessoas de modo geral, principalmente dos idosos (FERNANDES \& BOTELHO, 2007). Desse modo, os espaços físicos devem ser isentos de barreiras arquitetônicas e contemplar acessibilidade plena não só aos idosos ou pessoas com deficiências, mas todas as pessoas, indiferentemente de idade ou necessidade particular.

A preferência pela permanência em suas próprias casas (ageing in place) é o desejo da maioria dos idosos, entretanto, na impossibilidade dessa condição, as Instituições de Longa Permanência para Idosos - ILPI passam a ser a opção de moradia. Assim como os ambientes residenciais precisam estar adequados às limitações presentes nos idosos, estas instituições também precisam adequar sua infraestrutura de modo a garantir conforto, segurança e independência à pessoa idosa no desenvolvimento de suas atividades diárias.

Os espaços institucionais de moradia coletiva de idosos são regulamentados através da Resolução da Diretoria do Colegiado - RDC no 283 (2005) da Agência de Vigilância Sanitária - ANVISA, que estabelece critérios mínimos de funcionamento e avaliação das ILPIs. Esses ambientes são regidos também pela NBR 9050 (2004), norma técnica brasileira desenvolvida através dos preceitos do design universal com a função de estabelecer critérios e parâmetros técnicos que visam proporcionar acessibilidade de pessoas portadoras de deficiência ou com mobilidade reduzida a edificações, espaço, mobiliário e equipamentos urbanos.

\section{PROCEDIMENTOS METODOLÓGICOS}

Ambientes mal planejados ou não adaptados às necessidades dos idosos contribuem para o risco de prejuízos e constrangimentos que interferem diretamente na segurança e qualidade de vida dos usuários (PAIVA, SOBRAL \& VILLAROUCO, 2015). Essa situação ganha relevância quando os ambientes em questão são de moradia coletiva para idosos, indivíduos muitas vezes acometidos por déficit cognitivo e físico.

O presente artigo tem como objetivo a análise da acessibilidade de áreas internas e externas de 6 (seis) Instituições de Longa Permanência para Idosos - ILPI. As ILPIs 
investigadas são parte integrante de um projeto maior do Grupo de Pesquisa em Ergonomia Aplicada ao Ambiente Construído | Laboratório ErgoAmbiente, vinculado ao programa de Pós Graduação em Design da Universidade Federal de Pernambuco.

Constituíram a amostra 2 (duas) instituições mantidas e gerenciadas pelo poder público municipal, aqui referenciadas de "ILPIs públicas", 3 (três) ILPIs de caráter privado, custeadas pelos idosos, e 1 (uma) instituição mantida com recursos financeiros combinados - filantrópicos, próprios e governamentais.

Relativamente aos aspectos éticos, a pesquisa foi regularizada junto ao Comitê de Ética em Pesquisa da Universidade Federal de Pernambuco. Para os idosos voluntários e participantes da pesquisa foi solicitada a leitura e posterior chancela do Termo de Consentimento Livre e Esclarecido, uma vez sua anuência em participar da investigação.

O estudo classificado como qualitativo e exploratório utilizou a Metodologia para o Ambiente Construído - MEAC (Villarouco, 2008; 2009), e o Método do Espectro de Acessibilidade - MEA (BAPTISTA, 2003) para avaliação da acessibilidade espacial nas instituições.

Ressalta-se que no momento da coleta de dados da pesquisa, a versão em vigor da legislação brasileira pertinente à acessibilidade era a NBR 9050/2004.

\subsection{Método do Espectro de Acessibilidade - MEA}

O Método do Espectro de Acessibilidade - MEA (BAPTISTA, 2003), é um modelo conceitual desenvolvido para avaliação da acessibilidade de sistemas (produtos e ambientes) existentes, planejados ou em construção, auxiliando não só o usuário, mas também o projetista. Ancorado em normas técnicas, o MEA adota diferentes critérios conforme as habilidades e deficiências dos usuários, e tem como princípios básicos 0 Desenho Universal e a Acessibilidade, perpassando por várias disciplinas.

O MEA tem várias etapas: 1) identificação do sistema alvo (que nesta pesquisa corresponde às áreas externas de uma ILPI), estruturação do sistema (entender o ambiente e suas variáveis); 2) identificar e analisar as restrições e variáveis dependentes e independentes; 3) categorização do usuário relacionando suas necessidades à realização das tarefas envolvidas; 4) reunião e descrição de indicadores quantitativos e qualitativos para cada grupo de usuário.

Após definir estas questões, são escolhidas as áreas de passeio a serem avaliadas e os dados coletados quanto às características físicas do local são inseridos numa tabela desenvolvida no software Excel que utiliza fórmulas matemáticas. Tais dados são obtidos conforme as recomendações das normas técnicas de acessibilidade e compreendem as medidas na infraestrutura. Ao final, os resultados encontrados são transformados num feixe colorido que representará o nível de acessibilidade, que pode ir da cor vermelha (ambiente inacessível) até a cor azul (ambiente acessível).

\subsection{Metodologia para o ambiente construído - MEAC}

O usuário e o ambiente construído interagem de modo simultâneo e recíproco, quer seja de maneira consciente ou inconsciente (PINHEIRO \& ELALI, 2011), envolvendo nesse processo a percepção que se tem desse espaço. 
Assim, a adequação ergonômica do ambiente é de grande relevância para a promoção da segurança e conforto do usuário, no desenvolvimento de suas atividades tendo como envoltória esse espaço físico. Nessa perspectiva, a MEAC desenvolve uma abordagem ergonômica com objetivo de compreender, analisar e propor intervenções no ambiente com vistas à melhoria da relação contínua usuário-ambiente. A MEAC tem como elemento norteador os índices preconizados em legislações específicas, considerando também as necessidades constatadas por meio da percepção ambiental de seus usuários.

Desse modo, a MEAC é constituída por 2 (duas) fases; uma de ordem física e outra perceptiva, com geração de recomendações ergonômicas projetuais ou atitudinais para o ambiente. A primeira fase se divide em 3 (três) etapas: (i) Análise Global do Ambiente, (ii) Configuração Ambiental e (ii) Avaliação do Ambiente em Uso, com objetivo de entender e avaliar o sistema homem-atividade-ambiente, com a identificação de elementos facilitadores e inibidores das atividades. Para entender de que maneira o usuário percebe sua interação com o ambiente, a fase de ordem perceptiva utiliza técnicas da Psicologia Ambiental, tais como Mapa Mental ou Cognitivo, Constelação de Atributos, Poema dos Desejos, questionários, entre outros.

Ao final, é gerado o diagnóstico ergonômico, compilando os resultados de cada uma das etapas e chegando a um resultado final que aborde a situação encontrada sob o ponto de vista do pesquisador (ou projetista) e dos usuários do ambiente. Ou seja, o diagnóstico final busca atender aos interesses de todos os envolvidos com o ambiente.

\section{CONTEXTUALIZAÇÃO DO OBJETO DE ESTUDO}

As Instituições de Longa Permanência para Idosos aqui analisadas são parte integrante da pesquisa "Um olhar para a habitação coletiva para idosos - ILPI: Acessibilidade e Ergonomia para um envelhecer com dignidade", vinculada Grupo de Pesquisa em Ergonomia Aplicada ao Ambiente Construído | Laboratório ErgoAmbiente | UFPE. As instituições avaliadas apresentam gestão administrativa e financeira de naturezas distintas, identificadas doravante por ILPI 1 (instituição pública 1), ILPI 2 (instituição pública 2), ILPI 3 (instituição privada 1), ILPI 4 (instituição privada 2), ILPI 5 (instituição privada 3), e ILPI 6 (instituição mista), e a seguir serão brevemente descritas.

\subsection{ILPI 1 - Instituição pública 1}

Trata-se de uma instituição pública cuja principal fonte de recursos é o Instituto de Assistência Social e Cidadania - IASC, uma autarquia vinculada à Secretaria de Assistência Social da Prefeitura do Recife, sendo assim classificada como pública, mas também recebe doações. A ILPI 1 se situa na zona oeste do Recife e na época da pesquisa atuava com cerca de $90 \%$ de sua capacidade total de 24 idosos. Devido ao seu caráter público, recebe apenas idosos sem renda fixa, geralmente de rua, em abandono familiar e sem vínculos afetivos, encaminhados por hospitais, pela Polícia Militar do Recife e pelo IASC, e até mesmo por demanda espontânea. A ILPI 1 mantém o perfil de receber apenas idosos independentes (aqueles que possuem autonomia nos seus atos), mas as vezes abrigam temporariamente idosos dependentes enquanto estes não são direcionados a outra ILPI que possa recebê-los. 
Com área construída de aproximadamente $395 \mathrm{~m}^{2}$, a estrutura ILPI 1 se dá pela adaptação de uma casa residencial reformada e complementada no ano de 2003 para fins de abrigar idosos. A instituição se configura em dois blocos dispostos em "L" situados nos limites do terreno. Num ficam os dormitórios e no outro estão as áreas restritas aos funcionários, enfermaria, sala de atividades em grupo, área de convivência, refeitório e banheiro coletivo masculino. Entre os blocos encontra-se uma área verde, uma área de atividades, que na verdade é usada como varal de roupas, e poucas áreas de circulação.

A ILPI 1 é em pavimento térreo, conta com circulações amplas, portas com vão livre de $0,90 \mathrm{~m}$ e rampas como itens em favor a acessibilidade. No entanto, apresenta inúmeras falhas nesse quesito que, apesar de pouco afetar no dia a dia da instituição pelo caráter mais independente dos residentes, são fator de risco para quedas. São eles: Rampas de inclinação maiores que o permitido; Ausência de corrimãos ao longo de circulações e quando existentes estão mais altos do que deveriam; Não foram identificados pisos antiderrapantes; $\mathrm{Na}$ área externa tem pequenos desníveis e também sem corrimãos; Nenhum banheiro completamente acessível, sendo necessário obrigatoriamente ajuda de cuidador para cadeirantes; Quartos ocupados acima da capacidade máxima; Alguns quartos onde o layout não permite circulação e giro de cadeira de rodas; Sinalização tátil inexistente e a visual precária; E por fim, ausência de campainhas e iluminação de vigília.

\subsection{ILPI 2 - Instituição pública 2}

Situada na zona Oeste do Recife, a ILPI 2 é uma instituição pública de nível municipal de apoio aos idosos em dificuldades. Seus residentes são idosos na maioria em abandono familiar ou moradores de rua que chegam à instituição geralmente encaminhados pelo IASC. A ILPI 2 atua normalmente com sua capacidade máxima de 40 idosos, entretanto a maioria deles apresenta algum tipo de dependência.

Com área construída de 620,90m², a estrutura da ILPI 2 é a combinação de 2 terrenos, cuja casa foi ampliada para assumir a nova função em no ano de 2007 , quando foi inaugurada. Aparentemente não houve preocupação em atender às exigências de funcionamento normatizadas pela RDC n.283/05. Preocupando-se apenas em colocar rampas para vencer os desníveis existentes. A ILPI 2 está subdividida em dois blocos - casa principal e anexo. No bloco do anexo se localizavam salas de atividades e de psicologia, que foram adaptados recentemente para quartos de casal, segundo nova exigência do IASC.

A ILPI 2, apesar de agradável devido a grande área verde, apresenta diversos problemas de acessibilidade e adequação para idosos. - Sua área externa é sem corrimãos e tem piso desgastado com leves desníveis; Não possui áreas de convivência; Portas têm, em grande maioria, vãos menores que 0,80m; Rampas para os quartos femininos são todas com inclinação imprópria (Figura 01); Não há corrimãos nas circulações, exceto nas rampas que estão mais altas que o recomendado; Não possui sinalização visual ou tátil; Banheiros não são completamente acessíveis, muitas vezes pela instalação incorreta das barras de apoio; Os quartos apesar de guardarem a distância de no mínimo 0,8m entre camas, a maioria não tem o espaço de giro da cadeira de rodas; $E$ nenhum dos quartos tem luz de vigília e campainha de alarme. 


\subsection{ILPI 3 - Instituição privada 1}

A ILPI 3 se situa na zona oeste do Recife, é particular e recebe idosos aposentados pela prefeitura ou trazidos por familiares, que pagam a instituição e fornecem medicações e outros recursos necessários. Seu espaço se configura pela adaptação de duas residências paralelas, totalizando $640 \mathrm{~m}^{2}$, que não se comunicam sendo necessário ir à primeira casa para ter acesso à área para refeição, recepção e cozinha, espaços de grande utilização. Tem áreas externas cobertas e descobertas destinadas à convivência e atividades ao ar livre.

A ILPI 3 possui 15 dormitórios separados por sexo, com diferentes dimensões e número de 1 a 6 leitos para os 47 residentes na maioria dependentes na marcha e na realização das atividades de vida diária. Tomando como parâmetros as dimensões estabelecidas pela ANVISA, apenas os banheiros atendem a RDC $n^{\circ} 283 / 05$. Em geral, praticamente todos os ambientes estão subdimensionados, onde a discrepância é maior na sala de convivência que apresenta aproximadamente $0,23 \mathrm{~m}^{2}$ por pessoa quando deveria ter pelo menos $1,3 \mathrm{~m}^{2}$ por pessoa.

A ILPI 3 aparenta esforço em se adaptar para a acessibilidade na edificação, mas ainda apresenta problemas graves: Rampa com inclinação superior ao permitido com corrimão muito alto e incidindo dentro da largura da rampa; Apresenta corrimãos nas circulações internas, mas estão fora de norma; Já as circulações externas não contam com corrimãos; As portas têm $0,80 \mathrm{~m}$ que é o limite permitido, mas as dos banheiros tem vão de 0,70m comprometendo o acesso a eles; Ausência de luz de vigília e campainhas; Possui quartos com além da capacidade máxima; Não respeitam a distancia mínima de $0,80 \mathrm{~m}$ entre cama e também não há área de manobra para cadeiras de roda dentro dos quartos.

\subsection{ILPI 4 - Instituição privada 2}

A ILPI 4 fica na zona norte do Recife, é formada pela junção de três casas e conta com 36 residentes, $40 \%$ deles dependentes totais. Estes são trazidos pela família ou chegam por demanda espontânea. $O$ custo depende do número de residentes por dormitório, além do valor de medicamentos e da contratação de cuidador para dependentes, não inclusos na mensalidade. A área do hall de entrada é bastante usada pelos idosos independentes, tanto para lazer quanto atividades físicas na área descoberta. Outros espaços muito frequentados são as salas de convivência das três casas, onde ficam principalmente os dependentes.

Os $790 \mathrm{~m}^{2}$ de área construída estão distribuídos em 3 casas que não tem ligação coberta entre si. A primeira casa tem 3 pavimentos vencidos por escadas totalizando $410 \mathrm{~m}^{2}$, a segunda e terceira casas são térreas com $85 \mathrm{~m}^{2}$ e $130 \mathrm{~m}^{2}$ respectivamente. A ILPI 4 tem um total de 16 quartos separados por sexo que acomodam 3 ou 4 pessoas, grandes o suficiente para receber mobiliário dos residentes e ter área de manobra de cadeira de rodas.

Apesar do esforço para se adaptar, ainda assim pode-se notar diversos problemas de acessibilidade: Exceto alguns quartos, os ambientes estão subdimensionados; Quartos não possuem luz de vigília e campainha; Só há piso antiderrapante nas rampas e áreas externas; Como circulação vertical, tem as escadas com espelhos e pisos menores que recomendado e rampas com inclinação fora de norma, porém 
ambas com largura útil ideal; Há corrimãos tanto nas circulações internas quanto externas, porém estão irregulares quanto altura e diâmetro; E por fim as peças sanitárias e barras de apoio não têm alturas corretas.

\subsection{ILPI 5 - Instituição privada 3}

A ILPI 5 é uma instituição particular localizada na zona norte do Recife em bairro de classe média-alta, em que além da mensalidade, as despesas com produtos de higiene, medicamentos, atendimento de saúde e lavanderia, devem ser custeadas à parte. Os idosos chegam normalmente à instituição levados por familiares ou por demanda própria. Na ILPI 5 existem dois regimes de estadia, por internação e por diária. Os internos, ao todo 24 idosos, ficam acomodados em quartos duplos ou individuais separados por sexo. No sistema de diária, estavam sendo atendidos na época em torno de 10 idosos que passam o dia ou turnos, não utilizando quartos.

A instituição tem $313,70 \mathrm{~m}^{2}$ e dois blocos. O bloco $\mathrm{A}$ tem dois pavimentos e é onde funciona praticamente todas as atividades da ILPI 5, desde área de convivência e refeitório à farmácia e administração. Nele também se encontram 3 quartos duplos no térreo e no andar superior há 5 quartos individuais e um duplo. Enquanto o bloco B é constituído apenas por quartos e seus banheiros. Apenas o térreo estava concluído e nele há 4 quartos individuais e quatro duplos.

Nota-se claramente a intenção de se adequar as normas, a ILPI 5 tem piso antiderrapante nas áreas internas e externas, todas as portas tem mais $0,80 \mathrm{~m}$, os quartos tem número de ocupantes dentro do recomendado e todos com luz de vigília e campainha de alarme, mas nem todos tem tamanho adequado e não guarda a distância mínima entre camas. Mas há muitas outras falhas também: Não há corrimãos no bloco $B$, enquanto há no bloco $A$, mas nas escadas e rampa tem seção de difícil pega; o acesso entre blocos não é coberto nem guarnecido de corrimãos; Há sinalização visual, porém tátil só na rampa na área externa; Por fim, nenhum dos banheiros atendem completamente as normas de acessibilidade tendo problemas com instalação incorreta das barras e alturas das peças sanitárias inadequadas (Figura 2).

\subsection{ILPI 6 - Instituição mista}

A ILPI 6 está em Jaboatão dos Guararapes bem próxima da fronteira oeste do Recife e abrigava na época 120 idosos. Apesar de ser considerada entidade filantrópica, a ILPI 6 tem recursos públicos e privados. Foi criada na década de 40 para dar suporte ao grande número de mendigos em Recife e administrada na época pelas religiosas da Congregação Franciscana do Sagrado Coração de Jesus. Hoje é administrado pelo Rotary Club do Recife, um clube de serviços à comunidade local e mundial sem fins lucrativos que presta serviços voluntários não remunerados em favor da sociedade, mas as religiosas ainda tem forte presença no cotidiano da ILPI 6.

Com 7.941,99 $\mathrm{m}^{2}$ de área construída, a estrutura da instituição é composta por 9 blocos de edificações e uma igreja interligados por passeios e circulações cobertas, e envolto a uma grande área verde. As edificações têm morfologia pavilhonar semelhante aos modelos de abrigos de exclusão social para assistência a pacientes psiquiátricos e portadores de doenças infecciosas. Possuem espaços amplos com pé 
direito alto e iluminação deficitária. Os dormitórios foram particionados com divisórias de 1,90m em quartos menores de até 4 ocupantes para se adequar à $n^{0}$ 283/05.

Embora a ILPI 6 seja agradável, sua acessibilidade se apresenta comprometida. Nesse aspecto, os pontos relevantes a observar são: Circulações internas bem dimensionadas, mas sem corrimãos; Quartos permitem circulação e manobra de cadeira de rodas, e contêm campainha de emergência e luz de vigília; Banheiros são dotados de barras de apoio e alarme de emergência, mas tem peças sanitárias com alturas inadequadas; Há blocos com acesso através de degraus; Das 3 rampas encontradas apenas uma tem inclinação correta, porém todas tem corrimãos fora de norma no que se refere às seções (diâmetros).

Os revestimentos de piso são na maioria antiderrapantes, mas a transição entre os diferentes pisos apresenta desníveis. A circulação coberta entre blocos é dotada de guarda-corpo com corrimão em altura irregular, e com presença de banco em alvenaria em toda a extensão, que se torna interessante, já que a distância entre dormitórios e a fisioterapia é de até $160 \mathrm{~m}$. Por fim tem o passeio na área descoberta que não possui guarda-corpo, apresentando riscos de acidente pela existência de calha de águas pluviais nas laterais em nível abaixo do piso (Figura 3).

Figura 01: ILPI 2 - inadequação inclinação de rampa de acesso à área interna

Figura 02: ILPI5 - inadequação instalações de banheiro

Figura 03: ILPI 6 - Desnível nível de piso passeio | altura corrimão

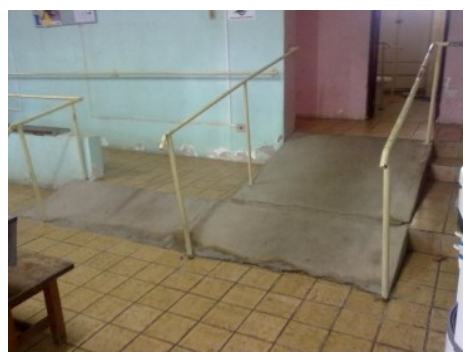

Figura 01

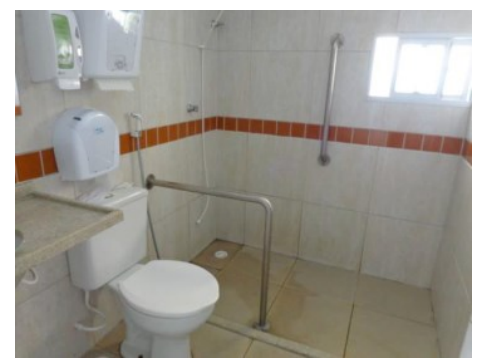

Figura 02

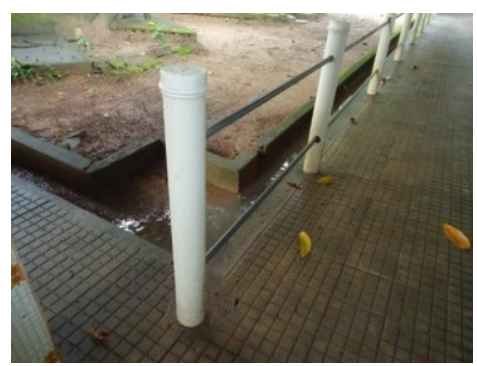

Figura 03

Fonte: Autores.

\section{ANÁLISE DA ACESSIBILIDADE FÍSICA EM AMBIENTES DE IDOSOS}

Os resultados encontrados foram obtidos através da aplicação da MEAC e do MEA e o Quadro 01, a seguir, traz um resumo do diagnóstico geral. Foram avaliados alguns itens importantes no que concerne à infraestrutura dos ambientes e à acessibilidade que proporcionam aos usuários. Estes itens fazem parte das recomendações da NBR9050/2004 e são considerados de grande relevância na promoção da autonomia, mobilidade, conforto e segurança.

Os itens analisados na infraestrutura, e considerados na avaliação da acessibilidade, tiveram como foco o uso do público geral de idosos. Mesmo as ILPIs sendo frequentadas por idosos com diversas condições de saúde, o objetivo da pesquisa não fez distinção de características físicas, cognitivas, nem de limitação específica, mas a movimentação e a usabilidade dos itens avaliados. 
Quadro 01: Comparativo da acessibilidade nas ILPIs segundo a NBR 9050/2004.

\begin{tabular}{|c|c|c|c|c|c|c|}
\hline & ILPI 1 & ILPI 2 & ILPI 3 & ILPI 4 & ILPI 5 & ILPI 6 \\
\hline \multicolumn{7}{|l|}{ ÁREAS EXTERNAS } \\
\hline Acessos (Largura passeios) & $\checkmark$ & $\checkmark$ & $\checkmark$ & $\checkmark$ & $\checkmark$ & $\checkmark$ \\
\hline Desniveis & $x$ & $x$ & $\checkmark$ & $\checkmark$ & $\checkmark$ & $x$ \\
\hline Corrimão (altura) & $x$ & $x$ & $x$ & $x$ & $\checkmark$ & $x$ \\
\hline Corrimão (seção) & $x$ & $x$ & $x$ & $x$ & $x$ & $\checkmark$ \\
\hline Sinalização tátil e visual & $x$ & $x$ & $x$ & $x$ & $x$ & $x$ \\
\hline Rampas - Inclinação & $x$ & - & $x$ & $x$ & $x$ & $x$ \\
\hline Revestimentos piso & $\checkmark$ & $x$ & $\checkmark$ & $\checkmark$ & $\checkmark$ & $x$ \\
\hline \multicolumn{7}{|l|}{ ÁREAS INTERNAS } \\
\hline Circulação (largura) & $x$ & $x$ & $\checkmark$ & $\checkmark$ & $\checkmark$ & $\checkmark$ \\
\hline Corrimão (altura) & $x$ & $x$ & $x$ & $x$ & $\checkmark$ & $x$ \\
\hline Corrimão (seção) & $x$ & $x$ & $x$ & $x$ & $x$ & $x$ \\
\hline Rampas - Inclinação & - & $x$ & - & $x$ & $x$ & $x$ \\
\hline Desníveis & $\checkmark$ & $\checkmark$ & $\checkmark$ & $\checkmark$ & $\checkmark$ & $\checkmark$ \\
\hline Revestimentos piso & $x$ & $x$ & $x$ & $x$ & $\checkmark$ & $x$ \\
\hline Portas (largura útil) & $\checkmark$ & $x$ & $x$ & $x$ & $\checkmark$ & $\checkmark$ \\
\hline Altura peças sanitárias & $x$ & $x$ & $x$ & $x$ & $x$ & $x$ \\
\hline Barras de apoio & $x$ & $x$ & $x$ & $x$ & $x$ & $x$ \\
\hline Iluminação noturna & $x$ & $x$ & $x$ & $x$ & $\checkmark$ & $\checkmark$ \\
\hline Chamada de emergência & $x$ & $x$ & $x$ & $x$ & $\checkmark$ & $\checkmark$ \\
\hline Sinalização tátil e visual & $x$ & $x$ & $x$ & $x$ & $x$ & $x$ \\
\hline Sinalização de emergência & $x$ & $x$ & $x$ & $x$ & $\checkmark$ & $\checkmark$ \\
\hline
\end{tabular}

Legenda: $\checkmark$ - Conformidade com a NBR 9050 /2004; X - não conformidade com a NBR 9050/2004.

O quadro comparativo acima evidencia que a maioria da infraestrutura das seis ILPIs não estão em conformidade com a acessibilidade mínima necessária para prover uma boa qualidade de vida para os idosos que assistem.

A largura dos passeios nas áreas externas foi o único item encontrado em todas as ILPIs e que estão em conformidade com a norma NBR9050/2004. Porém, vários itens também recomendados pela referida norma não aparecem em nenhuma das ILPIs. Ou seja, em nenhuma das instituições há uma correta inclinação das rampas de acesso e não há uma correta sinalização tátil ou visual nas áreas externas. Esta situação é preocupante, pois as áreas externas são os locais onde ocorre boa parte das relações interpessoais, onde os idosos se reúnem para realizarem as atividades coletivas, sejam elas de lazer ou um simples caminhar. Se estas áreas externas não atendem aos preceitos de acessibilidade podem potencializar os riscos de acidentes, principalmente as quedas.

Com relação às áreas internas, foi encontrada uma situação mais preocupante. Em todas as ILPIs analisadas, apenas um item da legislação foi identificado em consonância com a norma: os desníveis entre os ambientes. Em segundo lugar ficou as larguras das áreas de circulação. No entanto, quatro itens recomendados pela NBR 9050/2004 foram reprovados em todas as ILPIs. São eles: 1) seção dos corrimãos; 2) 
altura das peças sanitárias; 3 ) barras de apoio e; 4) sinalização tátil e visual. Partindo do pressuposto de que os idosos institucionalizados passam a maior parte da vida no interior das edificações, compreende-se que os riscos nas áreas internas são maiores do que nas áreas externas.

\section{CONSIDERAÇÕES FINAIS}

Analisar seis ILPIs de sistemas administrativos diferentes trouxe discussões relevantes no tocante à qualidade de vida dos idosos institucionalizados na Região Metropolitana do Recife. Embora tenham sistemas de gestão administrativa distintos, captação de recursos diferentes, e infraestruturas com características próprias, diversos problemas ergonômicos básicos foram encontrados.

O uso de metodologias e métodos ligados à acessibilidade em ambientes construídos são fundamentais para a compreensão das condições estruturais e consequentemente fomentar melhorias. Utilizar a MEAC e o MEA permitiu analisar diversos aspectos da infraestrutura das seis ILPIs e auxiliar tanto na identificação de problemas ergonômicos de concepção (projetos elaborados e executados sem considerar os preceitos da acessibilidade), quanto na identificação de más adequações e improvisos que mascaram riscos reais.

Independentemente do tipo de gestão adotado, a leitura ergonômica deve ser executada para fomentar melhorias na infraestrutura e dessa maneira fortalecer 0 papel social da ergonomia, que muitas vezes é vista como uma atividade técnica diretamente ligada à indústria.

\section{REFERÊNCIAS BIBLIOGRÁFICAS}

ABNT - ASSOCIAÇÃO BRASILEIRA DE NORMAS TÉCNICAS. NBR 9050: Acessibilidade a edificações, mobiliário, espaços e equipamentos urbanos. Rio de Janeiro, 2004.

BAPTISTA, A. H. N. Procedimentos metodológicos para a avaliação da acessibilidade de estruturas de circulação de pedestre com vistas ao projeto de "antropovias". 2003. $142 \mathrm{f}$. Dissertação (Mestrado em Design). Universidade Federal de Pernambuco, 2003.

BINS ELY, V. H. M. Ergonomia + Arquitetura: buscando um melhor desempenho do ambiente físico. In: Anais do $3^{\circ}$ Congresso Internacional de Ergonomia e Usabilidade de Interfaces Humano-Tecnologia. Rio de Janeiro: LEUI/PUC-Rio, 2003.

BRASIL. Agência Nacional de Vigilância Sanitária - ANVISA. Resolução da Diretoria Colegiada - RDC $\mathbf{N}^{\circ}$ 283/2005 - Regulamento Técnico que define normas de funcionamento para as Instituições de Longa Permanência para Idosos. Brasília, 2005. Disponível em: http://portal2.saude.gov.br/saudelegis/leg norma pesq consulta.cfm. Acesso em Junho 2016.

DOS SANTOS FERREIRA, Mario. Ergonomia no terceiro milênio: requisitos humanos para o objeto, para o ambiente, para a cidade. Nodo: Arquitectura. Ciudad. Medio Ambiente, v. 6, n. 11, p. 55-64, 2011.

ELALI, Gleice Azambuja. Relações entre comportamento humano e ambiência: Uma reflexão com base na psicologia ambiental. Rio Grande do Norte: UFRN, 2010. 
FERNANDES, A. A.; BOTELHO, M.A. Envelhecimento activo, envelhecimento saudável: 0 grande desafio. Fórum Sociológico n17 (II série): 11-16, 2007.

MONT'ALVÃO, C.; VILLAROUCO, V. Um novo olhar para o projeto: a ergonomia no ambiente construído. FAPERJ, 2AB, Teresópolis, RJ: 16, 2011.

NERI, A. L. Gerontologia | Gerontologia social | Geriatria. In NERI, Anita Liberalesso (org.) Palavras-chave em gerontologia, (pp 95-102). $3^{\text {a }}$ Edição. Campinas-SP: Editora Alínea, 2008.

PAIVA, M. M. B.; SOBRAL, E. R. A.; VILLAROUCO, V. The elderly and environmental perception in collective housing. In: AHFE 2015: 6th International Conference on Applied Human Factors and Ergonomics 2015 and the Affiliated Conferences. Procedia Manufacturing 3, p. 6505-6512, 2015.

PERRACINI M. R.; GAZZOLA J. M. Avaliação Multidimensional do idoso. In: PERRACINI, M. R.; FLÓ, C. M. (orgs). Funcionalidade e envelhecimento: fisioterapia: teoria e prática clínica. Rio de Janeiro: Guanabara Koogan, p.25-53, 2009.

PERRACINI, M. R. Planejamento e adaptação do ambiente para pessoas idosas. In: FREITAS, Elizabete V., \& al. (Orgs.). Tratado de geriatria e gerontologia (pp.1142-1151). Rio de Janeiro: Guanabara, Koogan, 2006.

PINHEIRO, J. Q.; ELALI, G. A. Comportamento socioespacial humano. In: Temas básicos em Psicologia Ambiental. CAVALCANTE, Sylvia; ELALI, Gleice A. (Orgs). Petrópolis: Ed.tora Vozes, 2011.

SILVA, Tânia L. K. da; CARDOSO, Eduardo. Preceitos ergonômicos aplicados ao desenvolvimento de um instrumento de avaliação de acessibilidade. Revista ação ergonômica [recurso eletrônico]: revista da Associação Brasileira de Ergonomia. Rio de Janeiro. Vol. 9, n. 1, p. 87-95, 2014.

STEINFELD, E.; MAISEL, J. Universal Design: Creating Inclusive Environments. New Jersey: John Wiley \& Sons, 2012.

VILLAROUCO, V. An ergonomic look at the work environment. In Proceedings of IEA 09: 17th World Congress on Ergonomics. China: Beijing, 2009.

VILLAROUCO, V. Construindo uma metodologia de avaliação ergonômica do ambiente. In: Anais do XV Congresso Brasileiro de Ergonomia - ABERGO. Porto Seguro - Bahia, 2008

VILLAROUCO, V. M. Modelo de avaliação pós-projeto: enfoques em variáveis cognitivas e ergonômicas. Tese. Programa de Pós-Graduação em Engenharia de Produção da Universidade Federal de Santa Catarina (PPGEP- UFSC), Florianópolis, 2001.

WAHL, H.-W.; WEISMAN, G. D. Environmental Gerontology at the Beginning of the New Millennium: Reflections on Its Historical, Empirical, and Theoretical Development. The Gerontologist, Vol .43, № 5, pp 616-627, 2003.

ZIMERMAN, G. I. Velhice: aspectos biopsicossociais. Porto Alegre: Artmed, 2000. 